\title{
Reflets
}

Revue ontaroise d'intervention sociale et communautaire

\section{Les cuisines collectives de Hearst}

\section{Pauline Guindon}

Volume 1, numéro 2, automne 1995

La santé communautaire en Ontario français : défis et espoirs

URI : https://id.erudit.org/iderudit/026089ar

DOI : https://doi.org/10.7202/026089ar

Aller au sommaire du numéro

Éditeur(s)

Reflets : Revue ontaroise d'intervention sociale et communautaire

ISSN

1203-4576 (imprimé)

1712-8498 (numérique)

Découvrir la revue

Citer cet article

Guindon, P. (1995). Les cuisines collectives de Hearst. Reflets, 1(2), 228-231.

https://doi.org/10.7202/026089ar

Tous droits réservés (C) Reflets : Revue ontaroise d'intervention sociale et communautaire, 1995

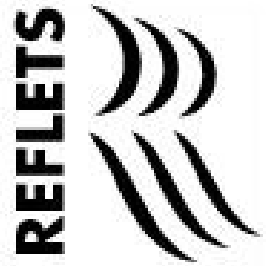

Ce document est protégé par la loi sur le droit d'auteur. L'utilisation des services d'Érudit (y compris la reproduction) est assujettie à sa politique d'utilisation que vous pouvez consulter en ligne.

https://apropos.erudit.org/fr/usagers/politique-dutilisation/ 


\section{Les cuisines collectives de Hearst}

\section{Pauline G uindon}

C ollaboratrice des auisines collectives, $\mathrm{H}$ earst

J'aimerais vous faire part d'un projet communautaire que la ville de $\mathrm{H}$ earst a mis sur pied, et pour lequel j'ai agi à titre de collaboratrice.

H earst est une petite ville d'environ 6000 habitants, à grande majorité francophone, située à quelque 600 kilomètres au nordouest de $\mathrm{N}$ orth Bay. $\mathrm{N}$ otre communauté est très active, très entreprenante et elle est reconnue pour son hospitalité. Elle a été la première ville en 0 ntario à se proclamer officiellement bilingue. Les villages environnants de $M$ attice à l'est, Jogues au sud et $C$ alstock à l'ouest se joignent à nous pour faire un coin de pays où il fait bon vivre. L'industrie forestière est la source première du gagne-pain de la région.

\section{Historique des cuisines collectives}

Au Pérou, les cuisines collectives existent depuis au moins 15 ans. En 1986, trois intervenantes montréalaises d'un organisme communautaire décident de se rencontrer pour planifier des repas et cuisiner ensemble afin d'arriver à boucler leur budget à la fin du mois. $\mathrm{D}$ ans ce quartier pauvre de $\mathrm{H}$ ochelaga- $\mathrm{M}$ aisonneuve, le mouvement s'est vite répandu parce que les femmes ont cru pouvoir mieux nourrir leur famille. À la suite de ces rencontres, elles ont réalisé qu'en plus d'économiser en cuisinant en grande quantité, elles sortaient de leur isolement, elles développaient leur autonomie en plus de contribuer à l'harmonie inter-raciale. C e moyen de s'entraider (à plusieurs niveaux) a donc plu à plusieurs 
personnes et continue de se propager. C haque groupe est un peu différent mais garde toujours le même objectif.

\section{Les cuisines collectives de Hearst}

À H earst, comme c'est souvent le cas ailleurs, il existe La soupe communautaire où les gens démunis se rencontrent tous les jeudis soirs afin de partager un bon repas, préparé par des bénévoles, et de rapporter chez-eux une boîte d'épicerie. Les responsables ont pensé que si les gens avaient la possibilité d'apprendre à cuisiner en économisant, un grand pas serait franchi. C'est alors que le Père R émi Lessard de la paroisse de St-Pie $X$ et le conseiller municipal André $R$ héaume ont uni leurs efforts pour demander une subvention au ministère de la Santé, afin de mettre sur pied des groupes intéressés aux cuisines collectives. Le projet a été subventionné sous l'égide du Bureau de Santé Porcupine de H earst, avec l'aide de deux diététiciennes, Joëlle Zorzetto et Patricia D esroches.

\section{Publicité et recrutement}

Afin de rejoindre la population de $\mathrm{H}$ earst et la convoquer à une soirée d'information, j'ai utilisé les médias suivants: notre radio communautaire $C I N N$, la radio $C B O N$, notre journal local $L$ e $N$ ord, notre câble communautaire et les bulletins paroissiaux. Des entrevues radiophoniques, des annonces gratuites et des pamphlets attrayants, voilà pour la publicité à bon marché! La soirée d'information comprend le visionnement portant sur le déroulement d'une cuisine collective, une courte présentation au sujet de notre façon de procéder et deslieux possibles pour cuisiner, ainsi qu'une période de questions et le tour est joué.

Il a été primordial de dresser une liste des groupes-cibles. Toutes les Eglises, catholique, unie, anglicane, pentecôtiste et assemblées chrétiennes, ont été rejointes. L'A ssociation des logis à prix modique, la Société de l'aide à l'enfance, le Bureau du bien-être social, le C entre d'embauche des jeunes, le $C$ entre 
d'alphabétisation, le R endez-vous familial, La soupe communautaire ont également reçu de l'information. D es soirées d'information ont été présentées aux groupes qui en ont fait la demande et aux autres qui, selon nous, auraient pu profiter de ce projet, dont La soupe communautaire.

À la suite de ces soirées d'information, un groupe se formait pour la prochaine étape de la planification.

\section{Planification}

La planification d'une cuisine collective est très importante. C hacun apporte sa ou ses recettes, les circulaires des épiceries et de l'argent. Ensemble, nous déterminons les recettes (environ 4 à 5 recettes par session). Le choix des recettes doit satisfaire les participants et participantes. II est recommandé de cuisiner pour 12 portions, à chaque recette. Le nombre de participants devrait être de 4 à 6 personnes. U ne soupe, 2 à 3 plats de résistance et un dessert font habituellement partie du menu. Le nombre de portions ne fait peur à personne puisque lorsque nous cuisinons, un bouillon de poulet est toujours prêt pour accueillir le reste des légumes. Comme résultat, nous avons une soupe pour 20 personnes! D écouverte de notre part: les desserts coûtent plus cher que les plats de résistance et sont sûrement moins nourrissants.

\section{Journée de cuisine}

Lors de la journée de cuisine, des consignes d'hygiène sont respectées. C hacun doit porter un filet pour cheveux et un tablier. L'ambiance de camaraderie est toujours au rendez-vous. C'est formidable de regarder des Autochtones pétrir la bannick, les hommes préparer des pâtés au saumon et entendre les femmes donner lestrucs particuliers de leur recette Q uelquefois, les groupes décident de partager le repas. A près la cuisson, les mets sont divisés et chacun rapporte ses portions préparées. V ient le temps du nettoyage, où tous participent au lavage de la vaisselle, du plancher, etc. 


\section{Notre but a-t-il été atteint?}

Tout au long de ce projet, un journal de bord a été tenu. Plus d'efforts ont été déployés pour atteindre les groupes-cibles. Le projet n'a pas réussi à intéresser ces personnes dans le besoin. Leur vraie pauvreté est peut-être de ne pas pouvoir se sortir de leur misère. Par ailleurs, les personnes qui ont participé ont constaté qu'il est possible de vraiment économiser en sachant comment s'y prendre. $\mathrm{N}$ ous avons cuisiné pour aussi peu que 75 cents la portion.

\section{Résumé}

U n total de huit groupes différents ont expérimenté les cuisines collectives dont des étudiants universitai res en résidence, des étudiants du projet Avenir, des hommes et des femmes du centre d'alphabétisation (Alpha-Popotte), des personnes végétariennes et des femmes sur le marché du travail.

Comme coordonnatrice de ce projet, j'ai apprécié la collaboration de ma communauté dans mes efforts. J'ai éprouvé une très grande satisfaction à voir les participantes et participants quitter le lieu de la cuisine, fiers d'apporter des plats nourrissants et peu dispendieux à la maison, de s'être fait de nouveaux amis, et surtout, de savoir que l'on peut économiser.

\section{Continuité}

Durant la période estivale, les trois groupes actifs des cuisines collectives de $\mathrm{H}$ earst ont pris congé. D ès septembre, nous projetons de recommencer. Inutile de mentionner que les nouvelles recettes commencent à s'accumuler pour les prochaines rencontres. 